D.O.I: $10.3895 / \mathrm{S} 1808-04482013000100011$

\title{
DIFERENÇAS E COMPLEMENTARIDADES ENTRE A LOGÍSTICA REVERSA, ISO 14000 E O GREEN SUPPLY CHAIN MANAGEMENT
}

\section{DIFFERENCES AND COMPLEMENTARITIES AMONG REVERSE LOGISTICS, ISO 14000 AND GREEN SUPPLY CHAIN MANAGEMENT}

\author{
Lineia Jollembeck Lopes ${ }^{1}$; Mário Sacomano Neto ${ }^{2}$; Valéria Rueda Elias Spers ${ }^{3}$ \\ ${ }^{1}$ Universidade Metodista de Piracicaba - UNIMEP - Piracicaba - Brasil \\ lineiajlopes@yahoo.com.br \\ ${ }^{2}$ Universidade Federal de São Carlos - UFSCar - São Carlos - Brasil \\ msacomano@ufscar.br \\ ${ }^{3}$ Universidade Metodista de Piracicaba - UNIMEP - Piracicaba - Brasil \\ vrueda@unimep.br
}

\begin{abstract}
Resumo
O Green Supply Chain Management (GSCM) vem sendo estudado e pesquisado de forma intensa nas últimas décadas, principalmente no âmbito internacional. Em paralelo, a logística reversa e os sistemas de gestão ambiental como a ISO 14000 são amplamente difundidos como práticas ambientais das empresas. Baseado nestes aspectos, este artigo visa apresentar os conceitos da logística reversa, da ISO 14000 e do GSCM, bem como explorar as diferenças $e$ complementaridades entre estas práticas, compilando e comparando os conceitos e as definições dos principais autores. Com a pressão das partes interessadas para atendimento aos requisitos ambientais, este artigo ganha importância uma vez que explora as práticas que auxiliam no alcance do comprometimento ambiental das organizações. Apesar deste fato, poucas pesquisas brasileiras foram encontradas sobre o tema. No decorrer da descrição dos conceitos, constata-se que a logística reversa é uma das práticas que compõe o GSCM. Já sobre a ISO 14000, autores defendem que ela é complementar ao GSCM. Outros argumentam que somente a implantação da ISO 14000 é suficiente para evidenciar as partes interessadas o comprometimento ambiental de uma organização. Como principal contribuição, este artigo visa auxiliar estudiosos e empresas brasileiras no embasamento quanto à adequação ambiental, bem como às exigências institucionais para a sustentabilidade.
\end{abstract}

Palavras-Chaves: cadeia de suprimentos verde; logística reversa; ISO 14000.

\section{Introdução}

O tema Green Supply Chain Management (GSCM) vem sendo estudado e pesquisado de forma intensa nas últimas décadas. Devido às pressões ambientais por conta do governo e da sociedade como um todo; a adoção do GSCM tem se expandido em diversos países, dentre eles, podem-se citar países da Europa, mais especificamente a Alemanha (CARTER et al, 1998; DARNALL et al, 2008a; NUNES; BENNETT, 2010; MORANA; SEURING, 2011; TESTA; 
IRALDO, 2010; THUN; MULLER, 2010; ZSIDIZIN; HENDRICK, 1998), a Hungria (DARNALL et al, 2008a; TESTA; IRALDO, 2010), o Reino Unido (ZSIDIZIN; HENDRICK, 1998), a Espanha (GONZÁLEZ-TORRE et al, 2004; GONZÁLEZ-TORRE et al, 2009); a Bélgica (GONZÁLEZTORRE et al, 2004), a França (TESTA; IRALDO, 2010), a Noruega (TESTA; IRALDO, 2010) e a Itália (BLENGINI; SHIELDS, 2010). Na Ásia, em países como a China, (ZHOU, 2009; ZHU; SARKIS, 2004; ZHU; SARKIS, 2006; ZHU et al, 2005; ZHU et al, 2007; ZHU et al, 2008a; ZHU et al, 2008b; ZHU et al, 2008c), a Coréia do Sul (LEE, 2008), Japão (NUNES; BENNETT, 2010; TESTA; IRALDO, 2010); as Filipinas (RAO, 2007) e a Malásia (ELTAYEB et al, 2011). Na Oceania, mais especificamente a Austrália (SIMPSON et al, 2007). Na América do Norte o Canadá (DARNALL et al, 2008a; TESTA; IRALDO, 2010; VACHON; KLASSEN, 2006a; VACHON; KLASSEN, 2006b) e os Estados Unidos (DARNALL et al, 2008a; DARNALL et al, 2008b; HANDFIELD et al, 2002; NUNES; BENNETT, 2010; TESTA; IRALDO, 2010; VACHON; KLASSEN, 2006a; VACHON; KLASSEN, 2006b; ZSIDIZIN; HENDRICK, 1998) e na América do Sul, mais especificamente o Brasil (BAENAS et al, 2011; JABBOUR; JABBOUR, 2009). Em paralelo ao crescimento do interesse pelo tema, as empresas estão continuamente em busca de novas ideias e métodos que lhes permitam alcançar a sustentabilidade ambiental.

De acordo com Green et al, (1996), o GSCM refere-se à maneira pela qual as inovações na gestão da cadeia de suprimentos e compras industriais são consideradas no contexto do ambiente. Zhu et al, (2008c) salientam que o GSCM emergiu com uma abordagem fundamental para empresas que querem se tornar ambientalmente sustentáveis.

Os stakeholders, ou as partes interessadas, vêm aumentando as cobranças pela melhoria no desempenho ambiental das empresas, principalmente os que exercem mais poder sobre elas (DARNALL et al, 2008a; LEE, 2008; RAO, 2007; SARKIS et al, 2011; SHARFMAN et al, 2007; SIMPSON et al, 2007; TESTA; IRALDO, 2010; ZHU et al, 2005; ZHU et al, 2008a). Conforme Sarkis et al, (2011), stakeholder é qualquer grupo ou indivíduo, interno ou externo a empresa, que pode ser ou é afetado no exercício das atividades de uma organização. Neste contexto, podem-se destacar os acionistas, investidores, empregados, fornecedores, sindicatos, associações empresariais, comunidade onde a empresa tem operações, governos e ONGs.

De acordo com Beamon (1999) a tendência de degradação ambiental indica a necessidade de mudança na filosofia de produção. A nova era ambiental representa um novo desafio para as empresas em todo o mundo. O desafio é desenvolver formas em que o crescimento industrial e a proteção do ambiente estejam em sintonia. Zhou (2009) acredita que a cadeia de suprimentos tem sido utilizada como alternativa estratégica que irá reescrever a competitividade no setor industrial e impulsionar os seus concorrentes a se desenvolverem. No entanto, para Sharfman et al, (2007) e 
Testa e Iraldo (2010), o GSCM não apresenta resultados no curto prazo, ele deve ser visto como um processo de longo prazo, que leva tempo para ser efetivamente aplicado dentro das empresas.

Com base na filosofia de gestão ambiental como uma vantagem competitiva, a dimensão ambiental da cadeia de suprimentos deve ser vista como um estímulo à inovação e alocação mais eficiente dos recursos empresariais e não apenas como uma exigência para o cumprimento regulamentar (ZHU; SARKIS, 2006). Adotar um Sistema de Gestão Ambiental (SGA) mais abrangente pode ser consistente com o interesse dos acionistas em investir cada vez mais nas organizações sustentáveis. As expectativas dos acionistas são que as empresas e as suas instalações sejam ambientalmente responsáveis. Desta forma, eles entendem que os riscos financeiros associados a uma má reputação ambiental sejam eliminados (DARNALL et al, 2008a). As regras institucionais ligadas à legislação ambiental também estimulam a adoção dessas práticas ambientalmente sustentáveis.

Para Zhu et al, (2005), a literatura acerca do tema GSCM vem crescendo à medida que as organizações e os pesquisadores percebem que a gestão ambiental não termina nos limites da organização. Baseado neste aspecto a problemática deste artigo consiste em explorar as especificidades dos conceitos da logística reversa, da ISO 14000 e do Green Supply Chain Management, pois o correto entendimento destes conceitos é fundamental para a prática de uma gestão sustentável, e, de acordo com a literatura, eles são constantemente confundidos. Para Pires (2010), ainda hoje existem profissionais atuando na área da Supply Chain Management (SCM), que entende a logística como sinônimo de transporte.

Como objetivo principal, o artigo apresenta os conceitos e explora as diferenças e complementaridades entre a logística reversa, a ISO 14000 e o GSCM. Para atingir este objetivo, foram compilados e comparados os conceitos e as definições dos principais autores do tema. Desta forma, o artigo contribui para os estudiosos e para as empresas brasileiras no embasamento quanto à adequação ambiental e as exigências institucionais para sustentabilidade. Além disso, apesar de o tema ser explorado internacionalmente desde a década passada, poucos estudos foram encontrados no Brasil. De acordo com Jabbour e Jabbour (2009), quando examinamos a literatura brasileira há uma lacuna teórico-empírica nesse campo de estudo e, esse fato foi um dos principais estímulos para o desenvolvimento deste artigo.

\section{Logística reversa e sistema de gestão ambiental: ISO 14000}

\subsection{Logística reversa}

De acordo com Rogers e Tibben-Lembke (1998), a logística reversa refere-se a todos os esforços para movimentar mercadorias do seu lugar de descarte ou destinação final, a fim de 
recuperar o seu valor. Desta forma, a logística reversa envolve o fluxo inverso da distribuição de produtos, fazendo parte da cadeia de suprimentos. Baseado neste aspecto, a logística reversa tornase uma das práticas do GSCM, a qual será detalhada no item 3.3.6.

\subsection{ISO 14000}

Inicialmente, a International Organization for Standardization (ISO) possuía diferentes siglas em diferentes línguas, por exemplo: ISO em inglês, OIN em francês. Devido a essas diferenças, seus fundadores decidiram dar-lhe um nome único, estabelecendo o termo ISO. A ISO desenvolve padrões baseados nas necessidades das empresas, setores e partes interessadas. A família ISO 14000 refere-se ao gerenciamento ambiental, o qual remete a todas as ações que a empresa implementa visando minimizar os efeitos de sua atividade no ambiente, bem como melhorar continuamente o seu desempenho (INTERNATIONAL ORGANIZATION FOR STANDALIZATION, 2011).

Apesar do crescente interesse em SGA e os benefícios que eles oferecem, sabe-se muito pouco sobre a relação que estes sistemas têm com a cadeia de suprimentos de uma organização, assim como se os adeptos do SGA promovem as práticas do GSCM (DARNALL et al, 2008b). Questões sobre o compromentimento ambiental das empresas surgem tendo em vista que o SGA não exige avaliação dos impactos ambientais de suas cadeias de suprimentos (ARIMURA et al, 2011; DARNALL et al, 2008b).

De acordo com Sarkis (2003), com a crescente aceitação da ISO 14001, cresce também o papel da gestão da cadeia de suprimentos com a prática ambiental. Neste contexto, deve ser considerado também que, muitas vezes, os clientes estão em lugares distantes ou em diferentes países, tornando impossível para eles verificar e acompanhar o desempenho ambiental de seus fornecedores. Desta forma, eles preferem um selo de acreditação internacional, como a certificação ISO 14001, que lhes asseguram o bom desempenho ambiental das empresas (RAO, 2007).

\section{O GSCM}

\subsection{História do GSCM}

A literatura do GSCM vem crescendo à medida que as organizações e os pesquisadores começam a perceber que a gestão ambiental não termina nos limites da organização (ZHU et al, 2005). A gestão ambiental abrange todas as atividades da empresa visando minimizar seus efeitos sobre o ambiente, assim como gerenciar ou responder aos efeitos do ambiente sobre a empresa. Isso inclui atividades como relatórios de regulamentação e conformidade, minimização na utilização de recursos, reciclagem, design para o ambiente, dentre outros (SHARFMAN et al, 2007). 
O início de 1990 acompanhou o surgimento e o crescimento dos negócios considerando o ambiente, as pesquisas em ecologia industrial e ecossistemas industriais, onde ambos remetem ao GSCM. Durante este tempo, o conceito emergente de GSCM foi surgindo e ganhando popularidade entre os pesquisadores e profissionais (SEURING et al, 2008). Srivastava (2007) destaca que na revolução da qualidade, na década de 1980, e na revolução de cadeia de suprimentos, na década de 1990, tornou-se claro que as melhores práticas buscam a integração da gestão ambiental com as operações.

Desde 1992, com a realização da ECO 92 no Rio de Janeiro, os paradigmas do desenvolvimento sustentável e responsabilidade ambiental têm se estendido muito além do cumprimento das regulamentações ambientais (RAO, 2007; SHARFMAN et al, 2007).

\subsection{Conceito do GSCM}

Para Zhu e Sarkis (2004), o GSCM vai desde o monitoramento reativo de programas de gestão ambiental às práticas mais proativas, tais como a reciclagem, recuperação, reconstrução e logística reversa.

Seuring et al, (2008) e Seuring e Muller (2008) definem a gestão sustentável da cadeia de suprimentos como a gestão dos fluxos de informação, material e capital, bem como a cooperação entre as empresas da cadeia de suprimentos, levando em consideração os objetivos das três dimensões do desenvolvimento sustentável: a econômica, ambiental e social.

O GSCM pode reduzir o impacto ecológico da atividade industrial sem sacrificar a qualidade, custo, confiabilidade, desempenho ou eficiência na utilização de energia. Trata-se de uma mudança de paradigma, passando do controle final, que visa atender às normas ambientais, para a situação não somente de minimizar os danos ecológicos, mas também de considerar o ganho econômico (SRIVASTAVA, 2007). As empresas cada vez mais investem tempo e energia no desenvolvimento da capacidade ambiental de seus fornecedores, pois eles têm se conscientizado que não conseguem atingir seus objetivos ambientais sozinhos (LEE, 2008).

Para Emmett e Sood (2010), o GSCM considera todos os efeitos ambientais em todos os processos da cadeia de suprimentos, desde a extração das matérias-primas até a destinação final dos produtos.

\subsection{Composição do GSCM}

De acordo com autores estudados, pode-se verificar no Quadro 1 a composição do GSCM: 
Quadro 1 - Principais autores e composição do GSCM

\begin{tabular}{|l|l|}
\hline \multicolumn{1}{|c|}{ Autor e ano } & \multicolumn{1}{c|}{ Composição } \\
\hline $\begin{array}{l}\text { Vachon e } \\
\text { Klassen, 2006(a) }\end{array}$ & $\begin{array}{l}\text { Incluem a aplicação da gestão ambiental, na qual abrange o gerenciamento de produtos } \\
\text { e atividades como a logística reversa, recuperação de produtos e remanufatura. }\end{array}$ \\
\hline Srivastava, 2007 & $\begin{array}{l}\text { Integra o pensamento ambiental na gestão da cadeia de suprimentos, incluindo o } \\
\text { projeto de produto, a busca e seleção de materiais, processos de fabricação, entrega do } \\
\text { produto final aos consumidores, bem como o gerenciamento deste produto após sua } \\
\text { vida útil. Seu escopo abrange muitas disciplinas, incluindo a gestão de riscos } \\
\text { ambientais, segurança dos produtos, segurança e saúde ocupacional, prevenção da } \\
\text { poluição, conservação de recursos e gestão de resíduos. }\end{array}$ \\
\hline Zhu et al, 2008(a) & $\begin{array}{l}\text { Defendem a implementação da compra verde integrada com o ciclo de vida do produto, } \\
\text { gestão de suprimentos do fornecedor, através do fabricante e do cliente, e fechando o } \\
\text { ciclo com a logística reversa. }\end{array}$ \\
\hline $\begin{array}{l}\text { Ninlawan et al, } \\
2010\end{array}$ & $\begin{array}{l}\text { Definem como aquisição verde + produção verde + distribuição verde + logística } \\
\text { reversa. }\end{array}$ \\
\hline $\begin{array}{l}\text { Nunes e Bennett, } \\
2010\end{array}$ & $\begin{array}{l}\text { Dividem as operações verdes em: prédios verdes, eco-design ou projetos verdes, supply } \\
\text { chain verde, produção verde e logística reversa. }\end{array}$ \\
\hline $\begin{array}{l}\text { Eltayeb et al, } \\
2011\end{array}$ & $\begin{array}{l}\text { Classificam nas seguintes categorias: projetos ecológicos, compras verdes, colaboração } \\
\text { ambiental dos fornecedores e logística reversa. }\end{array}$ \\
\hline
\end{tabular}

Fonte: Autoria própria (2011)

Baseado na literatura citada acima, para termos deste artigo serão utilizados as seguintes práticas: prédios verdes, operações verdes ou produção verde, projetos verdes e logística reversa, citadas por Nunes e Bennett (2010). Acrescenta-se nesta composição as práticas das compras verdes e análise do ciclo de vida do produto, citadas por Zhu et al, (2008a), a legislação ambiental e a avaliação de desempenho.

\subsubsection{Prédios verdes}

O objetivo principal dos prédios verdes é melhorar o desempenho ambiental de uma planta industrial durante as fases de construção e operação. Neste aspecto, considera a eficiência no consumo de água e energia, otimização do consumo de recursos materiais, bem como a qualidade ambiental interna, a inovação e o design (NUNES; BENNETT, 2010).

Como benefício, pode-se destacar a maior produtividade do trabalhador, redução nos custos com saúde e segurança, melhoria na qualidade ambiental interna, redução nos custos de manutenção, economia de energia e de água, assim como uma melhor gestão dos resíduos na fase de construção e operação (NUNES; BENNETT, 2010). Desta forma, sistemas de saúde e de segurança tendem a ser mais fáceis de serem gerenciados devido ao baixo nível de complexidade dos edifícios (NUNES; BENNETT, 2008; SPESHOCK, 2010). Emmett e Sood (2010) e Speshock (2010) acrescentam como benefício dos prédios verdes, a diminuição da geração dos gases de efeito estufa e dos custos financeiros com aquecimento.

Uma forma utilizada para avaliar edifícios verdes inclui o Leadership in Energy and Environmental Design (LEED). O LEED é um programa de certificação que foi desenvolvido pelo U.S. Green Building Council (USGBC) em março de 2000. Seguindo esta prática, o Green Building 
Council Brasil optou por disseminar no mercado o sistema de certificação LEED adaptado para a realidade brasileira (GBC BRASIL, 2011).

Uma série de empresas líderes de mercado adotam os edifícios verdes, pois tendo um design com instalações e consumo energia eficiente, economizam dinheiro e melhoram a produtividade do trabalhador, além de incorporar o "verde" em seus valores corporativos (ESTY; WINSTON, 2006).

\subsubsection{Projetos verdes}

Inicialmente, o projeto verde focava principalmente as melhorias técnicas dos produtos e processos, visando basicamente à redução dos custos ambientais (ZHU et al, 2008b). Atualmente, os projetos dos produtos têm uma influência significativa sobre o ambiente, pois é na fase de projeto que a função do produto, processo ou serviço é definida, bem como são selecionados as matérias-primas e insumos que serão utilizados (ELTAYEB et al, 2011).

O projeto verde é uma ferramenta útil para melhorar o desempenho ambiental das empresas e ajudar as organizações a fechar o ciclo da cadeia de suprimentos, abordando a funcionalidade do produto e ao mesmo tempo minimizando os impactos ambientais (ZHU et al, 2008c). A concepção ecológica visa reduzir a carga ambiental através do uso de materiais ecológicos, bem como facilitar a desmontagem do produto para reutilização, remanufatura ou reciclagem (NUNES; BENNETT, 2008; ZHU et al, 2008c).

As empresas podem investir conjuntamente em pesquisa e desenvolvimento de projetos, bem como dividir os direitos de propriedade intelectual. Este tipo de cooperação é geralmente chamado de "aliança estratégica", que pode não somente compartilhar as informações, mas também desenvolvê-las (SHAW et al, 2010). De acordo com Vachon e Klassen (2006b), a parceria do projeto verde é indicativa de uma capacidade de integração efetiva das tecnologias e know-how. Como tal, essa capacidade gera recursos difíceis de replicar, levando, por sua vez a uma vantagem competitiva. Portanto, o projeto verde é um determinante crucial, não apenas de competitividade, mas também das conseqüências ao ambiente (LYE et al, 2001).

\subsubsection{Ciclo de vida dos produtos}

As tendências para o longo prazo exigem das empresas novas maneiras para avaliar e reduzir os efeitos ambientais. A abordagem do ciclo de vida dos produtos demanda a análise do impacto ambiental durante todas as fases do ciclo, as quais poderão influenciar na carga ambiental de uma cadeia de suprimentos, desde a extração de recursos naturais, fabricação, utilização e reutilização, até a reciclagem ou descarte final (BAENAS et al, 2011; SHARFMAN et al, 2007; ZHU et al, 2005; ZHU et al, 2007). Beamon (2005) destaca que além destes fatores, a avaliação do ciclo de vida dos produtos visa identificar métodos para reduzir os impactos causados ao ambiente. 
De acordo com Sharfman et al, (2007), na adoção da abordagem do ciclo de vida três elementos são necessários: primeiramente, a compreensão de que as organizações afetam o ambiente natural através de todos os elementos de seu sistema; segundo, a redução no uso dos recursos através de uma produção e projetos eficientes, bem como gestão de resíduos; e terceiro, o esforço e o envolvimento de todas as partes da empresa, de seus fornecedores e de seus clientes.

A abordagem do ciclo de vida atualmente representa a base científica para vários indicadores de sustentabilidade ambiental, bem como para a comunicação verde e instrumentos de marketing verde. Por estas razões, dentre outras metodologias, a avaliação do ciclo de vida está cada vez mais sendo utilizada como uma ferramenta objetiva e confiável para medir o desempenho ambiental dos produtos e das empresas, bem como para entender a sustentabilidade ambiental da cadeia produtiva (BLENGINI; SHIELDS, 2010).

\subsubsection{Compras verdes}

Práticas externas do GSCM tornaram-se cada vez mais importantes para as empresas. É fato que o domínio da força de compras tem implicações importantes para as mudanças na cadeia de suprimentos (LEE, 2008). Para Nunes e Bennett (2010), as compras verdes visam incorporar critérios ambientais e preocupações em decisões de compras organizacionais e relacionamentos de longo prazo com os fornecedores.

A área de compras tem efeito significativo sobre o desempenho ambiental através de estratégias que incluem a redução e eliminação de desperdícios, a reciclagem e a reutilização de materiais (CARTER et al, 1998; NINLAWAN et al,2010). Insumos para a produção devem ser freqüentemente avaliados para assegurar que sua transformação em produtos e subprodutos causem danos mínimos ou não causem danos ao ambiente (ZSIDISIN; HENDRICK, 1998). Os compradores devem adquirir bens e serviços de fornecedores que são capazes de produzir produtos com os menores custos, com maior qualidade e dentro do menor tempo, mas que também sejam ambientalmente responsáveis na gestão dos seus processos (HANDFIELD et al, 2002).

As práticas relacionadas com GSCM englobam a abordagem baseada no monitoramento, que envolve as atividades de coleta e processamento de informações dos fornecedores, estabelecendo critérios de avaliação, os quais visam avaliar o desempenho ambiental dos produtos recebidos, bem como dos fornecedores que os forneceu (LEE, 2008). Em contraste com o monitoramento, a colaboração ambiental passa pela organização de compras em destinar recursos específicos para desenvolver atividades de cooperação para tratar questões ambientais na cadeia de suprimentos (VACHON; KLASSEN, 2006a).

Handfield et al, (2002) acrescentam que o sistema de avaliação de fornecedores pode ser de utilidade limitada no quesito ambiental. Há incertezas sobre como incluir desenvolvimentos 
recentes no desempenho ambiental, e quão importante esses acontecimentos possam ser em termos de desempenho ambiental global. Enquanto a avaliação de fornecedores e a decisão de seleção são rotineiras, poucas empresas têm desenvolvido uma metodologia para incorporar as questões ambientais nesta decisão.

\subsubsection{Operações verdes ou produção verde}

De acordo com Nunes e Bennett (2010), as operações verdes visam aumentar a eficiência e integrar continuamente os 4Rs na produção: reduzir, reutilizar, reciclar e remanufaturar. Elas referem-se a todos os aspectos relacionados com a fabricação, remanufatura, uso, manuseio, logística e gestão de resíduos dos produtos. Podem ser consideradas como práticas que contribuem para a melhoria do desempenho ambiental nas operações das empresas. Assim, considerando os processos gerais da função de operações, podemos destacar o planejamento de produção, desenvolvimento de produtos e processos, gerenciamento de cadeia de suprimentos, produção, e, finalmente, o pós-venda.

As operações das organizações têm um impacto direto sobre o ambiente através de sua configuração e gestão do processo de produção, bem como no projeto de produto, por isso, é importante para as organizações incorporarem o desempenho ambiental ao desempenho operacional (VACHON; KLASSEN 2006b).

Para Emmett e Sood (2010), a produção verde estimula a inovação, integração e melhoria dos produtos, processos e serviços, portanto, é uma estratégia organizacional que foca na rentabilidade, utilizando processos operacionais ambientalmente amigáveis.

\subsubsection{Logística reversa}

A definição de logística reversa, a partir de uma perspectiva ambiental, enfoca principalmente o retorno de produtos recicláveis ou reutilizáveis (SARKIS, 2003). A logística reversa está associada com as atividades de reciclagem, reparação, reutilização e reprocessamento, bem como com as tarefas de recolhimento, desmontagem e transformação dos produtos em componentes e/ou materiais usados (BEAMON, 1999; ELTAYEB et al, 2011; NINLAWAN et al, 2010).

Para Nunes e Bennett (2010), o objetivo principal da logística reversa é planejar, implementar e controlar os fluxos reversos durante o processo e após o uso de produtos, principalmente no final da sua vida útil. Como principais benefícios, podem-se destacar a redução dos encargos ambientais sobre a disposição final dos produtos, reuso de componentes com valor financeiro agregado e redução de custos em aterros e responsabilidade ambiental.

Os ciclos de materiais e devoluções de produtos formam uma parte importante dos processos relacionados com o alto potencial de reduzir a carga ambiental (MORANA; SEURING, 2011). 
Apesar da importância do GSCM para a ecologia industrial, a integração dos fluxos logísticos em uma cadeia de suprimentos verde ainda permanece como uma questão crítica no GSCM pelas seguintes razões: primeiramente, do ponto de vista estratégico organizacional, é difícil coordenar as atividades de todos os membros da cadeia; segundo, há uma falta de modelos adequados como ferramentas para gerenciar a logística e os fluxos associados a cada membro da cadeia. Além disso, o comportamento do cliente final, por exemplo, a disposição de devolver os produtos utilizados, e outros fatores externos tais como as políticas e regulamentações governamentais, também influenciam no desempenho de uma cadeia de suprimentos verde (SHEU et al, 2005).

Para Gonzáles-Torre et al, (2004), as razões para a promoção das práticas da logística reversa são econômicas e ambientais. O fluxo da logística reversa representa um instrumento sem precedentes para o desenvolvimento econômico e operacional das atividades da empresa, bem como um diferencial na busca de vantagens competitivas por meio de práticas ambientalmente corretas (BAENAS et al, 2011; GONZÁLEZ-TORRE et al, 2004; GONZÁLEZ-TORRE et al, 2009).

\subsubsection{Legislação ambiental}

A legislação ambiental foi acrescentada pelos autores às práticas do GSCM, visto que uma organização ambientalmente sustentável deve cumprir com os requisitos legais bem como acompanhar as suas atualizações.

De acordo com Machado Júnior et al, (2011), a preocupação ambiental é um tema presente nas discussões e reflexões da sociedade, dos poderes públicos e das organizações. Thun e Muller (2010) salientam que, em contraste com o passado, atualmente os governos reconhecem os efeitos do comportamento que põe em perigo o ambiente e, buscam neutralizá-los através da legislação. Para Lorenzett et al, (2011), o mundo vive um período onde o equilíbrio ambiental está em ascensão, onde os órgãos ambientais estão cada vez mais atuantes e a legislação ambiental cada vez mais rigorosa.

Conforme Rao (2007), para as empresas terem sucesso ao trabalhar com clientes globais, a cadeia de suprimentos deve observar as normas ambientais compatíveis com os regulamentos locais, bem como observar as normas ambientais estabelecidos no país onde o cliente se situa.

Para Hoffman (1999), as pressões regulatórias são cobertas por mandatos legais. Organizações que não cumprem com os requisitos regulamentares estão sujeitas ao risco de sanções legais, inclusive de perder a sua autorização de funcionamento, podendo também incorrer em multas e penalidades. O medo de sanção legal é considerada a principal razão pela qual as organizações implementam as atividades ambientais proativamente. 


\subsubsection{Avaliação de desempenho}

GSCM é uma prática cada vez mais difundida entre as empresas que buscam melhorar o desempenho ambiental (TESTA; IRALDO, 2010). Visando atender exigências do governo, dos clientes e das partes interessadas, as organizações estão incluindo em suas avaliações o cumprimento aos requisitos de responsabilidade ambiental e social (SHAW et al, 2010).

Nos primeiros estágios evolutivos da gestão ambiental, as organizações separavam o desempenho ambiental do desempenho operacional, no entanto, com a evolução das organizações, elas começam a integrar os objetivos ambientais no âmbito dos seus objetivos operacionais (BEAMON, 1999). Para Shaw et al, (2010), há uma nítida diferença entre a teoria e a prática no desenvolvimento de uma medida de performance ambiental, para eles, as organizações precisam de mais orientação sobre a gestão do desempenho ambiental na cadeia de suprimentos, quer seja através de sistemas de gestão ambiental já existente ou de legislação governamental.

O desempenho econômico é normalmente a meta mais importante para empresas que desejam implementar práticas de gestão ambiental, especialmente para as empresas nos países em desenvolvimento (ZHU; SARKIS, 2004). A evidência mais recente indica que as organizações que adotam SGA podem se beneficiar financeiramente (DARNALL et al, 2008a). Nunes e Bennett (2010), alertam que não é sempre que iniciativas de gestão ambiental irão retornar lucro, no entanto, quanto mais as empresas considerarem a importância da gestão dos intangíveis, mais as questões ambientais e de sustentabilidade estarão presentes nos objetivos estratégicos das empresas. Tsai e Hung (2009) acrescentam que quando os custos e a avaliação de desempenho não estão integrados, o significado de custo ambiental ou desempenho ambiental se tornará ambígua, porque os seus efeitos são desconhecidos. Blengini e Shields, (2010), alertam que do ponto de vista da empresa, um problema permanente de todos que atuam de maneira ambientalmente sustentável é a dificuldade de identificar e capturar a vantagem competitiva.

Pode-se acrescentar ainda que, da mesma forma que um cliente impõe especificações de qualidade, certificados de sistemas de gestão ambiental dos fornecedores tornam-se outra condição (VACHON; KLASSEN, 2006a). Porém, Thun e Muller (2010) alertam que os clientes não estão necessariamente dispostos a pagar mais por produtos verdes, eles os preferem quando os seus preços são iguais aos demais. Para Eltayeb et al, (2011), os resultados inconclusivos levantam a questão de quais são os resultados reais que podem ser realizados a partir da adoção de iniciativas verdes da cadeia de suprimentos.

Seuring e Muller (2008) mencionam que três aspectos são freqüentemente mencionados como obstáculos para a implementação do GSCM na cadeia de suprimentos sustentável: custo elevado, esforço de coordenação e complexidade, e comunicação insuficiente ou ausente na cadeia de suprimentos. 


\section{Compilação e comparação das práticas ambientais}

Apresenta-se no Quadro 2 o conceito central da logística reversa, da ISO 14000 e do GSCM, assim como o foco de atuação de cada um deles. Destacam-se também as partes envolvidas na execução das práticas ambientais, bem como a forma de evidenciar o atendimento destas práticas às partes interessadas.

Quadro 2 - Resumo das práticas da logística reversa, ISO 14000 e GSCM

\begin{tabular}{|c|c|c|c|c|}
\hline Item & Conceito central & Foco de atuação & $\begin{array}{c}\text { Partes } \\
\text { envolvidas }\end{array}$ & $\begin{array}{c}\text { Forma evidenciar } \\
\text { atendimento }\end{array}$ \\
\hline $\begin{array}{l}\text { Logística } \\
\text { reversa }\end{array}$ & $\begin{array}{l}\text { Logística reversa trabalha o fluxo } \\
\text { de mercadorias do ponto de } \\
\text { consumo até o ponto de origem. } \\
\text { Busca recapturar o valor do produto } \\
\text { ou providenciar o descarte } \\
\text { apropriado (ROGERS; TIBBEN- } \\
\text { LEMBKE, 1998). }\end{array}$ & $\begin{array}{l}\text { Fluxo inverso dos } \\
\text { materiais } \\
\text { vendidos/distribuí } \\
\text { dos ou fluxo de } \\
\text { produtos } \\
\text { devolvidos. }\end{array}$ & $\begin{array}{l}\text { Clientes, } \\
\text { distribuidores, } \\
\text { fabricantes } \\
\text { fornecedores. }\end{array}$ & $\begin{array}{l}\text { Comprovantes } \\
\text { fiscais de retorno, } \\
\text { reutilização, } \\
\text { reciclagem e/ou } \\
\text { remanufatura, ou } \\
\text { da destinação final } \\
\text { dos materiais. }\end{array}$ \\
\hline ISO 14000 & $\begin{array}{l}\text { ISO } 14001 \text { especifica requisitos } \\
\text { para sistema de gestão ambiental. } \\
\text { Estes requisitos são auditados } \\
\text { visando verificar a conformidade } \\
\text { com a norma (INTERNATIONAL } \\
\text { ORGANIZATION } \\
\text { STANDALIZATION, 2011). }\end{array}$ & \begin{tabular}{l}
\multicolumn{3}{l}{ Gerenciamento } \\
dos impactos \\
ambientais da \\
organização.
\end{tabular} & $\begin{array}{l}\text { Toda } \\
\text { organização. }\end{array}$ & $\begin{array}{l}\text { Certificado ISO } \\
\text { emitido pelo órgão } \\
\text { certificador. }\end{array}$ \\
\hline GSCM & $\begin{array}{l}\text { O GSCM busca melhorar as } \\
\text { práticas ambientais das empresas, } \\
\text { porque procura gerir os seus } \\
\text { impactos ambientais através das } \\
\text { suas redes. Organizações que } \\
\text { adotam as práticas do GSCM tem } \\
\text { uma estratégia ambiental mais } \\
\text { abrangente (ARIMURA et al, } \\
\text { 2011). }\end{array}$ & $\begin{array}{l}\text { Gerenciamento } \\
\text { dos impactos } \\
\text { ambientais da } \\
\text { organização, } \\
\text { fornecedores e } \\
\text { clientes. }\end{array}$ & $\begin{array}{l}\text { Toda a cadeia } \\
\text { de suprimentos, } \\
\text { incluindo } \\
\text { fornecedores, } \\
\text { distribuidores e } \\
\text { clientes. }\end{array}$ & $\begin{array}{l}\text { Certificado ISO, } \\
\text { relatórios sociais e } \\
\text { a não incidência de } \\
\text { pendências ou } \\
\text { notificações } \\
\text { ambientais. }\end{array}$ \\
\hline
\end{tabular}

Fonte: Autoria própria (2011)

Pode-se constatar na exploração da literatura que a logística reversa é uma das práticas que compõe o GSCM, visto que ela atende parte do fluxo de materiais enfocando basicamente o retorno de produtos recicláveis, reutilizáveis ou produtos após a sua vida útil.

Para Darnall et al, (2008b), as empresas que adotam SGA podem ter poucas razões para adotar o GSCM, uma vez que elas podem inserir-se no mercado como sendo ambientalmente proativas. De acordo com Arimura et al, (2011) e Darnall et al, (2008b), a ISO 14001 não exige que as empresas avaliem os impactos ambientais na cadeia de suprimentos. Desta forma, constata-se que o GSCM é mais amplo que a certificação ISO aumentando o envolvimento e comprometimento ambiental das organizações.

Para Arimura et al, (2011), as empresas que têm certificação ISO 14001 podem implementar GSCM com menor custo. Para os autores Darnall et al, (2008b), as habilidades necessárias para adotar GSCM são complementares aos recursos necessários para o sucesso na adoção de um SGA, pois ambos os sistemas incentivam as empresas a reduzir o uso de insumos e diminuir o 
desperdício, os quais são importantes para minimizar os impactos ao ambiente. Adeptos do SGA também podem ter maior facilidade durante a implementação do GSCM por possuir o conhecimento tácito necessário para gerenciar os impactos ambientais de sua cadeia de suprimentos.

Darnall et al, (2008b) acrescentam ainda que as organizações que adotam o SGA e GSCM, possuem competências internas comparáveis e suportam pressões institucionais semelhantes. Juntos, eles oferecem um sistema mais abrangente na definição e estabelecimento da sustentabilidade entre as organizações empresariais. Por estas razões, pode-se supor que os adotantes do SGA são mais propensos a adotar as práticas do GSCM. No entanto, quando SGA são adotadas na ausência de GSCM, os benefícios ambientais tendem a diminuir.

\section{Considerações finais}

Atualmente as empresas vêm investindo no marketing verde e desta forma conscientizando as partes interessadas sobre a importância da preservação ambiental (BLENGINI e SHIELDS, 2010). Da mesma forma, as partes interessadas pressionam as empresas a terem atitudes ambientalmente responsáveis (DARNALL et al, 2008a; LEE, 2008; RAO, 2007; SARKIS et al, 2011; SHARFMAN et al, 2007; SIMPSON et al, 2007; TESTA, IRALDO, 2010; ZHU et al, 2005; ZHU et al, 2008a). Seuring et al, (2008) ressaltam que problemas no desempenho ambiental ou social podem facilmente afetar a marca e as negociações das ações destas organizações, tornando desempenho da cadeia de suprimentos um foco competitivo crítico.

Referente aos temas tratados neste artigo destaca-se que a logística reversa exerce papel fundamental como uma das práticas do GSCM devido englobar o fluxo inverso da distribuição, facilitando desta forma a reutilização, remanufatura, reciclagem e destinação correta dos resíduos.

Com relação à gestão ambiental da cadeia de suprimentos, pode-se afirmar que o GSCM é mais abrangente que a ISO 14000, pois enquanto a ISO envolve a organização, o GSCM envolve toda a cadeia, considerando fornecedores, distribuidores e clientes, exigindo desta forma maior envolvimento e comprometimento destes frente aos resultados ambientais. Neste caso, o certificado ISO 14000 pode ser uma das formas de evidenciar este envolvimento e comprometimento ambiental da organização às partes interessadas.

Embora Darnall et al, (2008b) citarem a possibilidade das empresas que possuem certificado ISO 14001 inserir-se no mercado como sendo ambientalmente proativas, concorda-se com eles quando mencionam que o GSCM e a ISO 14000 são complementares, pois juntos oferecem um sistema mais abrangente no estabelecimento da sustentabilidade organizacional. Destaca-se também o fato das empresas que possuem um SGA terem mais facilidade e benefícios ao implantar o GSCM 
devido já possuírem as competências e os conhecimentos necessários (ARIMURA et al, 2011 e DARNALL et al, 2008b).

Conforme citado na introdução deste artigo, contata-se que várias pesquisas foram realizadas sobre o tema, porém, novos estudos devem ser desenvolvidos, principalmente sobre os conceitos, adoção das práticas e os benefícios do GSCM.

\begin{abstract}
Green Supply Chain Management (GSCM) has been intensively researched on the last decades, mainly internationally. In parallel of this, reverse logistics and environmental management systems such as ISO 14000, are widely published as company's environmental practices. Based on this aspect, this article presents the concepts of reverse logistics, ISO 14000 and GSCM. It explores the differences and complementarities among them and compares the concepts and definitions of the main authors as well. Stakeholder's pressures over the organizations to deal with social and environment requirements makes this study to gain importance, once it explores practices and ways to evidence the environmental commitment of the companies. Besides this fact, just a few Brazilian researches were found about this subject. In the progress of this description, it became evident that reverse logistics is one of the practices which compose the whole GSCM. With regard ISO 14000, some authors hold that this ISO and GSCM are complementary to each other. Others argue that just the ISO 14000 adoption would be enough to evidence to the stakeholders the environmental commitment of the organization. As the main contribution, this article can be used by researchers and Brazilian companies as a reference about the environmental suitability and the institutional requirements for sustainability as well.
\end{abstract}

Key-words: Green supply chain management; reverse logistics; ISO 14000.

\title{
Referências
}

ARIMURA, T. H.; DARNALL, N.; HATAYAMA, H. Is ISO 14001 a gateway to more advanced voluntary action? a case for green supply chain management. Journal of Environmental Economics and Management, v. 61, p. 170-182, 2011.

cross ref

BAENAS, J. M. H.; CASTRO, R.; BATTISTELLE, R. A. G.; GOBBO JUNIOR, J. A. A study of reverse logistics flow management in vehicle battery industries in the midwest of the state of São Paulo (Brazil). Journal of Cleaner Production, v. 19, n. 2-3, p. 168-172, 2011.

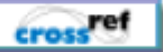

BEAMON, B. M. Designing the green supply chain. Logistics Information Management, v. 12, n. 4, p. 332-342, 1999.

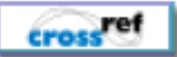

BEAMON, B. M. Environmental and sustainability ethics in supply chain management. Science and Engineering Ethics, v. 11, n. 2, p. 221-234, 2005.

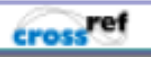

BLENGINI, G. A.; SHIELDS, D. J. Green labels and sustainability reporting: overview of the building products supply chain in Italy. Management of Environmental Quality: An International Journal, v. 21, n. 4, p. 477-493, 2010. 
CARTER, C.; ELLRAM, L. M.; READY, K. J. Environmental purchasing: benchmarking our German counterparts. International Journal of Purchasing and Materials Management, v. 34, n. 4, p. 28-38, 1998.

DARNALL, N.; HENRIQUES, I.; HENRIQUES, P. Do environmental management systems improve business performance in an international setting? Journal of International Management, v. 14, n. 4, p. 364-376, 2008(a). cross ref

DARNALL, N.; JOLLEY, G. J.; HANDFIELD, R.Environmental management systems and green supply chain management: complements for sustainability? Business Strategy and the Environment, v. 17, n. 1, p. 30-45, 2008(b). cross ref

ELTAYEB, T. K.; ZAILANI, S.; RAMAYAH, T. Green supply chain initiatives among certified companies in Malaysia and environmental sustainability: investigating the outcomes. Resources, Conservation and Recycling, $v$. 55, n. 5, p. 495-506, 2011.

cross ref

EMMETT, S.; SOOD, V. Green supply chains: an action manifest. United Kingdom: John Wiley \& Sons, 2010.

ESTY, D. C.; WINSTON, A. S. Green to gold: how smart companies use environmental strategy to innovate, create value, and build competitive advantage. New Heaven : Yale University, 2006.

GONZÁLEZ-TORRE, P. L; ADENSO-DÍAZ, B.; ARTIBA, H. Environmental and reverse logistics policies in european bottling and packaging firms. International Journal Production Economics, v. 88, n. 1, p. 95-104, 2004.

GONZÁLEZ-TORRE, P.; ÁLVAREZ, M.; SARKIS, J.; ADENSO-DÍAZ, B. Barriers to the implementation of environmentally oriented reverse logistics: evidence from the automotive industry sector. British Journal of Management, v. 21, n. 4, p. 1-16, 2009.

cross ref

GREEN BUILDING COUNCIL BRASIL. Certificação LEED. Disponível em:

<http://www.gbcbrasil.org.br/pt/index.php?pag=certificacao.php>. Acesso em: 25 jun. 2011. 14h53'.

GREEN, K.; MORTEN, B.; NEW, S. Purchasing and environmental management: interactions, policies and opportunities. Business Strategy and the Environment, v. 5, p. 188-197, 1996.

cross ref

HANDFIELD, R.; WALTON, S. V.; SROUFE, R.; MELNYK, S. A. Applying environmental criteria to supplier assessment: a study in the application of the analytical hierarchy process. European Journal of Operational Research, v. 141, n. 1, p. 70-87, 2002.

cross ref

HOFFMAN, A. J. Institutional evolution and change: environmentalism and the U.S. chemical industry. The Academy of Management Journal, v. 42, n. 4, p. 351-371, 1999.

INTERNATIONAL ORGANIZATION FOR STANDALIZATION. About ISO. Disponível em: < http://www.iso.org/iso/home/about.htm>. Acesso em 15 jun 2011. 11h:59'.

INTERNATIONAL ORGANIZATION FOR STANDALIZATION. ISO 14000: Environment management. Disponível em: < http:/ http://www.iso.org/iso/home/standards/management-standards/iso14000.htm>. Acesso em 15 jun 2011. 11h:40'.

JABBOUR, A. B. L. S.; JABBOUR, C. J. C. Are supplier selection criteria going green? case studies of companies in Brazil. Industrial Management \& Data Systems, v. 109, n. 4, p. 477-495, 2009.

cross ref

LEE, S.Y. Drivers for the participation of small and medium-sized suppliers in green supply chain initiatives. Supply Chain Management: an International Journal. v. 13, n. 3, p. 185-198, 2008. 
LORENZETT, D. B.; ROSSATO, M. V; NEUHAUS, M. Medidas de gestão ambiental adotadas em um posto de abastecimento de combustíveis. Revista Gestão Industrial, v. 7, n. 3, p. 1-21, 2011. Disponível em:

<http://revistas.utfpr.edu.br/pg/index.php/revistagi/article/view/635>. Acesso em 02 abr 2013. 20:54'.

LYE, S.; LEE, S. G.; KHOO, M. K. A design methodology for the strategic assessment of a product's ecoefficiency. International Journal of Production Research, v. 39, n. 11, p. 2453-2474, 2001.

cross ref

MACHADO JUNIOR, C.; SOUZA, M. T. S.; FURLANETO, C. J. A ação ambiental das organizações junto aos seus stakeholders. Revista Gestão Industrial, v. 7, n. 1, p. 210-227, 2011. Disponível em:

<http://revistas.utfpr.edu.br/pg/index.php/revistagi/article/view/559>. Acesso em 02 abr 2013. 20:32'.

MORANA, R.; SEURING, S. A three level framework for closed-loop supply chain management-linking society, chain and actor level. Sustainability, v. 3, n. 4, p. 678-691, 2011.

cross ref

NINLAWAN, C.; SEKSAN, P.; TOSSAPOL, K.; PILADA, W. The implementation of green supply chain management practices in electronics industry. Proceedings of International MultiConference of Engineers and Computer Scientists, v. 3, mar. 2010.

NUNES, B.; BENNETT, D. The contribution of modularity to green operations practices. Brazilian Journal of Operations \& Production Management, v. 5, n. 2, p. 93-108, 2008.

NUNES, B.; BENNETT, D. Green operations initiatives in the automotive industry: an environmental reports analysis and benchmarking study. Benchmarking: An International Journal, v. 17, n. 3, p. 396-410, 2010.

PIRES, S. R. I. Gestão da cadeia de suprimentos: conceitos, estratégias, práticas e casos. $2^{\mathrm{a}}$ ed. São Paulo: Atlas; 2010 .

RAO, P. Greening of the supply chain: an empirical study for SMES in the Philippine context. Journal of Asia Business Studies, v. 1, n. 2, p. 55-66, 2007.

cross ref

ROGERS, D. S.; TIBBEN-LEMBKE, R. S. Going backwards: reverse logistics trends and practices. Nevada (USA): University of Nevada, 1998.

SARKIS, J. A strategic decision framework for green supply chain management. Journal of Cleaner Production, v. 11, n. 4, p. 397-409, 2003.

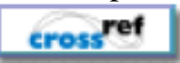

SARKIS, J.; ZHU, Q.; LAI, K. An organizational theoretic review of green supply chain management literature. International Journal Economics, v. 130, n. 1, p. 1-15, 2011.

SEURING, S.; SARKIS, J.; MULLER, M.; RAO, P. Sustainability and supply chain management - an introduction to the special issue. Journal of Cleaner Production, v. 16, n. 15, p. 1545-1551, 2008.

cross

SEURING, S.; MULLER, M. From a literature review to a conceptual framework for sustainable supply chain management. Journal of Cleaner Production, v. 16, n. 15, p. 1699-1710, 2008.

cross ref

SHARFMAN, M.; ELLINGTON, R. T.; MEO, M. The next step in becoming "green": life-cycle oriented environmental management. Business Horizons, v.40, n. 3, p. 13-22, 2007.

cross ref

SHAW, S.; GRANT, D. B.; MANGAN, J. Developing environmental supply chain performance measures. Benchmarking: An International Journal, v. 17, n. 3, p. 320-339, 2010. 
SHEU, J-B.; CHOU, Y-H.; HU, C-C. An integrated logistics operational model for green-supply chain management. Transportation Research Part E, v. 41, n. 4, p. 287-313, 2005.

cross ref

SIMPSON, D.; POWER, D. SAMSON, D. Greening the automotive supply chain: a relationship perspective. International Journal of Operations \& Production Management, v. 27, n. 1, p. 28-48, 2007.

cross ref

SPESHOCK, C. H. Empowering green initiatives with IT: a strategy and implementation guide. New Jersey: John Wiley \& Sons, 2010.

SRIVASTAVA, S. K. Green supply-chain management: a state-of-the-art literature review. International Journal of Management Reviews, v. 9, n. 1, p. 53-80, 2007.

cross ref

TESTA, F; IRALDO, F. Shadows and lights of GSCM (green supply chain management): determinants and effects of these practices based on a multi-national study. Journal of Cleaner Production, v. 18, n. 10-11, p. 953-962, 2010.

cross ref

THUN, J-H.; MULLER, A. An empirical analysis of green supply chain management in the German automotive industry. Business Strategy and the Environment, v. 16, n. 2, p.119-132, 2010.

TSAI, W. -H.; HUNG, S-J. A fuzzy goal programming approach for green supply chain optimisation under activitybased costing and performance evaluation with a value-chain structure. International Journal of Production Research, v. 47, n. 18, p. 4991-5017, 2009.

cross ref

VACHON, S.; KLASSEN, R. D. Extending green practices across the supply chain: the impact of upstream and downstream integration. International Journal of Operations \& Production Management, v. 26, n. 7, p. 795-821, 2006(a).

cross ref

VACHON, S.; KLASSEN, R. D. Green project partnership in the supply chain: the case of the package printing industry. Journal of Cleaner Production, v.14, n. 6-7, p. 661-671, 2006(b).

cross ref

ZHOU, F. Study on the implementation of green supply chain management in textile enterprises. Journal of Sustainable Development, v. 2, n. 1, p. 75-79, 2009.

ZHU, Q.; SARKIS, J. Relationships between operational practices and performance among early adopters of green supply chain management practices in chinese manufacturing enterprises. Journal of Operations Management, v. 22, n. 3, p. 265-289, 2004.

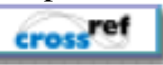

ZHU, Q.; SARKIS, J. An inter-sectoral comparison of green supply chain management in China: drivers and practices. Journal of Cleaner Production, v. 14, n. 5, p. 472-486, 2006.

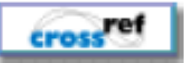

ZHU, Q.; SARKIS, J.; GENG, Y. Green supply chain management in China: pressures, practices and performance. International Journal of Operations \& Production Management, v. 25, n. 5, p. 449-468, 2005.

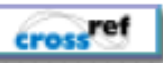

ZHU, Q.; SARKIS, J.; LAI, K. Green supply chain management: pressures, practices and performance within the chinese automobile industry. Journal of Cleaner Production, v. 15, n. 11-12, p. 1041-1052, 2007. 
ZHU, Q.; SARKIS, J.; LAI, K. Confirmation of a measurement model for green supply chain management practices implementation. International Journal Production Economics, v. 111, n. 2, p. 261-273, 2008(a).

\section{cross ref}

ZHU, Q.; SARKIS, J.; CORDEIRO, J. J.; LAI, K. Firm-level correlates of emergent green supply chain management practices in the Chinese context. Omega: the International Journal of Management Science, v. 36, n. 4, p. 577-591, 2008(b).

\section{cross ref}

ZHU, Q.; SARKIS, J.; LAI, K. Green supply chain management implications for “closing the loop”, Transportation Research Part E, v. 44, n. 1, p. 1-18, 2008(c).

ZSIDISIN, G. A.; HENDRICK, T. E. Purchasing's involvement in environmental issues: a multi-country perspective. Industrial Management \& Data Systems, v. 98, n. 7, p. 313-320, 1998.

cross ref

\section{Dados dos autores:}

Nome completo: Lineia Jollembeck Lopes

Filiação institucional: Universidade Metodista de Piracicaba - UNIMEP - Piracicaba - Brasil

Departamento: Mestrado Profissional em Administração

Função ou cargo ocupado: Mestranda

Endereço completo para correspondência: Rua Santa Cruz, 150, Apto 21 - Bairro Alto - Piracicaba

- SP - Brasil - 13419-020

Telefones para contato: 19 3301-3832 / 19 8197-4419

e-mail: lineiajlopes@yahoo.com.br

Nome completo: Mário Sacomano Neto

Filiação institucional: Universidade Federal de São Carlos - UFSCar - São Carlos - Brasil

Departamento: Departamento de Engenharia de Produção (DEP/UFSCar)

Função ou cargo ocupado: Professor

Endereço completo para correspondência: Avenida Miguel Damha, 1400, Jardim Guanabara,

Damha II, Casa 472 - São Carlos - SP - 13565-814

Telefones para contato: 16 9766-1154

e-mail:msacomano@ufscar.br

\section{Nome completo: Valéria Rueda Elias Spers}

Filiação institucional: Universidade Metodista de Piracicaba - UNIMEP - Piracicaba - Brasil

Departamento: Faculdade de Gestão de Negócios (FGN) / Programa de Pós-Graduação Mestrado Profissional e Doutorado em Administração (PPGA)

Função ou cargo ocupado: Professora 
Endereço completo para correspondência: Rua Barão de Piracicamirim, 1162 - São Dimas Piracicaba - SP - 13416-005

Telefones para contato: 19 9782-6961

e-mail:vrueda@unimep.br

Enviado em: 23/12/2011

Aprovado em: $23 / 03 / 2013$ 